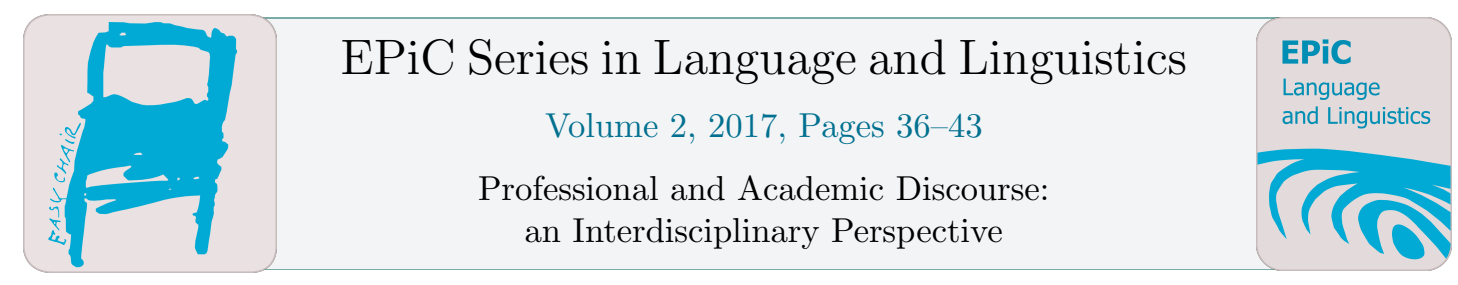

\title{
Analysis of EFL Writing in Secondary Education
}

\author{
Ana Cristina Lahuerta Martínez \\ University of Oviedo, Asturias, Spain \\ lahuerta@uniovi.es
}

\begin{abstract}
The aim of this paper is to examine secondary education learners' performance in L2 writing production using the complexity, accuracy, and fluency constructs. Results show that the measures of fluency, accuracy, grammatical and lexical complexity progress in a significant way: fourth grade students outperform first graders in the aforementioned measures. Secondly, fewer correlations between the writing measures used and the general quality of the compositions are found among the older students than among the younger ones, indicating that the correlations change depending on learners' age. Thirdly, 1st year students exhibit a higher ratio of errors, both in general and also by error category, although only two types decrease significantly in 4th year students: syntactic and spelling errors. Lastly, we find that errors tend to develop in a non-linear way.
\end{abstract}

Keywords: L2 writing development; CAF; secondary education.

\section{Introduction}

Writing is one of the skills comprised in the learning of a foreign language (FL). Many researchers contend that the pivotal aspects of L2 writing performance can effectively be captured by the complexity, accuracy, and fluency (CAF) constructs (Rosmawati, 2014, pp. 76-77). Fluency gauges "how comfortable the second language writer is with producing language" (Wolfe-Quintero et al., 1998, p. 13). Accuracy can be defined as the absence of deviations from a particular linguistic norm, it is "the ability to be free from errors while using language to communicate in either writing or speech" (WolfeQuintero et al., 1998, p. 33). Grammatical complexity means that "a wide variety of basic and sophisticated structures are available and can be accessed quickly" (Wolfe-Quintero et al., 1998, p. 69), and lexical complexity means that "a wide variety of basic and sophisticated words are available and can be accessed quickly" (Wolfe-Quintero et al., 1998, p. 101). Therefore, complexity describes the learners' language knowledge while accuracy measures the appropriateness of language use, and fluency the automaticity of language use. These three constructs, as a triad, gauge the learners' development as a whole (Rosmawati, 2014). 


\section{Review of the Literature}

Cross-sectional studies like those by Lorenzo and Rodríguez (2014), and Yang, Lu, and Weigle (2015) investigate written development. Lorenzo and Rodríguez (2014) approached the appearance and evolution of academic written language structures in a second language, in formal bilingual contexts. The authors analysed a corpus of historical narratives of subjects from the third year of secondary education to the second year of post-compulsory secondary education (baccalaureate). The study employed complexity measures, among them the mean length of sentence, mean length of clause, clauses per sentence, verb phrases per T-unit, dependent clauses per clause, coordinate phrases per clause, complex nominals per T-unit, and complex nominals per clause. The lexical complexity analysis used 25 different measures such as diverse type-token ratio measures, variation of different parts of speech, verb sophistication, and lexical range. Results (2014, p. 70) showed that learners in the lowest grades produced an amalgamated language, characterized by a lack of dependent clauses, T-units, and coordinate phrases. However, this language skill was consolidated in higher grades as all measures examined improved. Although changes were continuous they were nevertheless unstable, with higher peaks reaching significance levels in the uppermost course.

Yang et al. (2015) focused on syntactic complexity, which was conceptualized and measured as a multi-dimensional construct with interconnected sub-constructs. They examined the relationship between ESL writing syntactic complexity and writing quality, as well as the role of topic in the relationship. The participants were ESL graduate students who wrote two argumentative essays on two different topics. The authors found syntactic complexity as measured by mean length of sentences and mean length of T-unit to be a significant predictor of writing scores across the two topics (2015, pp. 60$62)$.

Longitudinal studies are also to be found in the literature. Those of Knoch et al. $(2014,2015)$ found significant writing development but limited to certain measures in students who had spent some period of study abroad. Navés, Torras, and Celaya (2003) and Godfrey, Treacy, and Tarone (2014) also report longitudinal studies, but comparing the performance of different groups. Navés et al. (2003) investigated the development of the written production of six groups of primary and secondary education learners using fluency, accuracy, and complexity measures. For fluency, they employed eight measures, such as the total number of words, the total number of clauses, or the total number of sentences. For accuracy, they took into account the error-free sentences, the percentage of error-free sentences, and the number of rejected units. For grammatical complexity, they used twenty-seven features, such as the number of subordinated clauses, the number of coordinated clauses, the number of non-finite nodes, the ratio of clauses per sentence, the ratio of non-finite nodes per clause, the ratio of non-finite node per sentence, and the ratio of subordinated clauses per clause. Finally, they employed 13 measures of lexical complexity, such as noun tokens, noun types, adjective tokens, adjective types, primary verb types, open class words, or lexical density.

One of the main findings of this study (2003) was that there seem to be two different patterns of development in EFL written production depending on learners' age. Pattern I shows almost no interlanguage development between the first three groups of younger learners (aged below 12) and then a steady increase in the older groups (aged above 12) for most syntactic complexity measures and for adverbs (lexical complexity). Pattern II shows a steady development in the first four groups of younger learners (aged below 14). This development stops in the older groups (aged above 14) for accuracy, fluency, and some lexical measures. Another relevant finding was that accuracy, fluency, syntactic and lexical complexity do not develop in tandem, but correlate differently depending on the learners' age group and the strength of the relationship between the measures in the four components (2003, p. 123).

For their part, Godfrey et al. (2014) examined the writing of eight university learners of French-four during study abroad and four in on-campus courses--over the period of a semester. This study applied measures focused on the complexity, accuracy, fluency, and form-function relationships of 
writing samples collected at the beginning and end of the semester. The measure of fluency was the total number of words per essay. Accuracy was measured by counting the percentage of correct instances in which a student had to make a decision about gender. Syntactic complexity was analysed with a clause/T-unit analysis (2014, p. 54). Results (2014, p. 56) showed that progress toward more advanced academic L2 writing occurred for both groups of students, although in different ways. Students in both groups improved their fluency in writing, as measured by length of their essays, but the on-campus group seemed to increase essay length more than the study abroad group did. On a measure of accuracy, the study abroad group increased both their use of French gendered nouns and their accuracy in gender marking more than the on-campus group did. A T-unit analysis showed that, while both groups increased the syntactic complexity in their writing, the on-campus group improved more than the study abroad group did. Both groups'use of linguistic forms and expressions to make supported claims and use of appropriate discourse markers improved, while the on-campus group increased their hedging of such claims more than the study abroad group.

Other studies adopt a dynamic perspective. In this view, CAF constructs are treated as dynamic (sub)systems, whose growth is expected to be non-linear and displays a high degree of variability as the expression of development (Larsen-Freeman, 2006, 2012). Some of these studies, namely LarsenFreeman (2006) and Rosmawati (2014), examining written development over a period of time, found out significant improvement in the groups studied, together with a great degree of individual variability and fluctuations.

Other two studies conveying a dynamic approach were carried out by Verspoor et al. (2012), and Thewissen (2013). Verspoor et al. (2012) analysed texts written by a group of learners of English as an L2 in their first and third year of high school. They investigated 64 separate variables involving sentence constructions, clause constructions, verb phrase constructions, chunks, the lexicon, and accuracy measures across five different proficiency levels, from beginner to intermediate (2012, p. 241). Findings showed that at the higher proficiency levels all measures looked at improved: more complex constructions at all levels emerged and fewer errors occurred. Results also showed that measures of sentence length, lexical complexity, the total number of dependent clauses, chunks, and errors, and the use of present and past tense distinguished between proficiency levels of writing expertise. However, almost all specific constructions showed non-linear development, variation, and changing relationships among the variables. The data suggest that learners who go from level 1 to 2 are especially busy learning words; after a certain threshold of vocabulary has been reached, the learners seem to focus more on syntactic complexity between levels 2 and 3 , which continues a bit between levels 3 and 4 , but there it is mixed with lexical measures. After most syntactic constructions are in place, there is a focus again on lexical matters between levels 4 and 5 (2012, p. 257).

Thewissen (2013) investigated second language accuracy developmental trajectories via an errortagged version of an English as a Foreign Language (EFL) learner corpus. Learner essays were annotated for errors and they were rated according to the Common European Framework of Reference for Languages descriptors for linguistic competence. This study showed that it was lexis that progressed most strongly from the intermediate to the advanced levels. Findings showed a non-linear developmental pattern as only two error types displayed a linear, progress-only type of development (viz., the total errors and lexical single errors). Progress and stabilization and stabilization-only patterns accounted for $94 \%$ of all error types. Progress-only and regressive types of development, however, constituted the exception rather than the rule (2013, p. 95). This study also suggests that both stabilization and regression should not in and of themselves be negatively interpreted and may in fact at times be the result of growing L2 capacities, such as increasing levels of complexity, especially at the more advanced levels. 
As expected, the literature reviewed above reveals that the analysis of the measures used to assess written competence shows significant improvement across proficiency levels as well as over time. The studies also show a reduction in the number of errors as proficiency increases. In order to help research in this field so that practitioners achieve a better understanding of L2 writing development, we decided to gather further data regarding the secondary education stage.

\section{Study}

\subsection{Aim of the Study}

The aim of this paper is to explore and measure language development by gauging the progress in learners' performance in L2 production. In order to understand stages in language development, we will carry out an exploration into the multi-components of written development using the complexity, accuracy, and fluency constructs. We will compare the written competence of first and fourth grade secondary education students.

The following research questions are the focus of the study:

1. Is there a significant difference in writing between both groups in every measure? If not, which measures (if any)--fluency, accuracy, grammatical complexity, lexical complexity--progress in a significant way in both levels?

2. Is there a significant relationship between the overall grade and the measurements--fluency, accuracy, grammatical complexity, and lexical complexity? Is there a significant relationship among the measurements--fluency, accuracy, grammatical complexity, and lexical complexity?

3. Which level makes more overall errors? What kind of errors--syntactic, morphological, or lexical-has the largest percentage in each level? Does the overall number of errors decrease significantly? Which subtypes of errors decrease significantly in the levels? Do some errors increase instead of decreasing significantly?

\subsection{Participants}

A total of 123 students, belonging to 2 different levels of secondary education ( $1^{\circ}$ Compulsory Secondary Education $(\mathrm{CSE})=69 ; 4^{\circ}$ Compulsory Secondary Education $\left.(\mathrm{CSE})=54\right)$ at a state-funded private school in a city in northern Spain took part in the study.

\subsection{Method}

During the month of January of 2015, students were asked to write an essay in English. The topic of the essay for all of them was "The Television".

\subsection{Procedure}

To measure fluency we counted the total number of words. In addition, we used sentence length (total number of words divided by total number of sentences) and clause length (total number of words divided by total number of clauses) as measures of the fluency of writing. For accuracy, the measures used were error-free clauses ratio (total number of error-free clauses divided by total number of clauses) and errors per word ratio (total number of errors divided by total number of words). As additional measures, we also calculated the number of syntactic, morphological, lexical, punctuation, and spelling errors divided by the number of words. Regarding the grammatical complexity measures, we used the sentence complexity ratio (total number of clauses divided by total number of sentences). Finally, for 
lexical complexity we used the ratio of the number of word types to the square root of two times the word tokens.

Errors were analysed and scored as syntactic, morphological, or lexical. Thus, syntactic errors consisted of errors of word order, errors resulting from the absence of constituents, and errors in combining sentences. Word-order errors included errors in the order of major constituents (such as pragmatically unacceptable deviations from SVO) and minor constituents (such as adverb placement). Errors resulting from the absence of constituents included deletion of a major constituent (subject, verb, or object), and sentence fragments that lacked finite verbs. Errors in sentence combining included errors in complementation. Morphological errors included errors in nominal morphology (plural, case, possessive, and person), errors in verbal morphology (tense, subject-verb agreement, and passive formation), errors in determiners and articles, errors in prepositions, and errors in derivational morphology (e.g., lack of suffixes, etc.). As lexical errors, we counted lexical-idiomatic, or vocabulary errors.

\section{Results and Discussion}

Our study shows that the measures of fluency, accuracy, grammatical and lexical complexity progress in a significant way. We observe (see Table 1) that fourth grade students outperform first graders in all the measures of writing used. These results support previous findings by Verspoor et al. (2012), Rosmawati (2014), and Yang and Sun (2015).

\begin{tabular}{|c|c|c|c|c|}
\hline & & $\mathrm{n}$ & Mean & s. d. \\
\hline \multirow[t]{2}{*}{ Fluency Total n. words } & 1st year CSE & 69 & 79.72 & 33.36 \\
\hline & 4th year CSE & 54 & $194.50 *$ & 55.65 \\
\hline \multirow{2}{*}{ Fluency Sentence length } & 1st year CSE & 69 & 13.10 & 6.33 \\
\hline & 4th year CSE & 54 & $18.47^{*}$ & 5.58 \\
\hline \multirow[t]{2}{*}{ Fluency Clause length } & 1st year CSE & 69 & 7.09 & 2.36 \\
\hline & 4th year CSE & 54 & $7.77 *$ & 1.98 \\
\hline \multirow[t]{2}{*}{ Accuracy Error-free clause ratic } & o1st year CSE & 69 & 0.15 & 0.16 \\
\hline & 4th year CSE & 54 & $0.25 *$ & 0.18 \\
\hline \multirow[t]{2}{*}{ Accuracy Errors per word ratio } & 1st year CSE & 69 & $0.25^{* *}$ & 0.14 \\
\hline & 4th year CSE & 54 & 0.15 & 0.06 \\
\hline \multirow[t]{2}{*}{ Grammatical Complexity } & 1st year CSE & 69 & 1.88 & 0.79 \\
\hline & 4th year CSE & 54 & $2.43^{*}$ & 0.70 \\
\hline \multirow[t]{2}{*}{ Lexical Complexity } & 1st year CSE & 69 & 1.80 & 0.56 \\
\hline & 4th year CSE & 54 & $2.48 *$ & 0.69 \\
\hline$* \mathrm{p}<0.01 * * \mathrm{p}<0.05$ & & & & \\
\hline
\end{tabular}

Table 1: Difference in CAF measures across levels.

With respect to the second research question regarding the correlations between the writing measures used and the general quality of the compositions, fewer correlations are found in the older students than in the younger ones. It seems that a possible accuracy-complexity trade-off effect may be operating from first to fourth year with increasing risk taking (i.e., increasing complexity) affecting significant improvement (i.e., accuracy). For instance, the case for clause length, which is correlated 
significantly with the overall score in the 1st year but not in the 4th could be explained by the fact that, compared with the lower stage students, the participants at the higher level wrote more coordinated clauses as well as much more, and more complicated, subordinated ones. The difficulty posed by that fact could have affected scores negatively. Similarly, the results for lexical complexity, which also correlated significantly with composition scores in 1st CSE but not in 4th, could be explained by the fact that fourth year students have already acquired a large vocabulary and try to make use of it. It would appear that those of them who take more risks trying to express their ideas in written form make more lexical mistakes. This agrees in part with Verspoor et al.'s (2012) results, which showed that students focus on lexical matters at the higher stages of high school, so maybe the group in our study was trying to adjust the vocabulary acquired over some time.

For their part, the correlations found between the various measures of written competence used change depending on learners' grade, a finding consistent with results by Navés et al. (2003) that showed that the correlations between measures depended on learners' age.

With respect to the number of errors in each level, first year students exhibited a higher ratio of errors in general and in each of the specific error categories. We observe that, as proficiency increases, so does the learners' overall level of accuracy in English. However, only two types of errors showed a significant difference between groups: syntactic errors and spelling errors $\left(1^{\circ} \mathrm{M}=0.05 ; 4^{\circ} \mathrm{M}=0.023\right.$, $\mathrm{p}<0.01 ; 1^{\circ} \mathrm{M}=0.05 ; 4^{\circ} \mathrm{M}=0.02, \mathrm{p}<0.01$ ). First and fourth year students commit mostly morphological errors followed by syntactic, lexical, spelling, and, finally, punctuation errors.

It seems that as competence progresses, syntax improves, whereas students continue to show incomplete and variable acquisition of grammatical morphemes. All syntactic errors decrease from first to fourth grade and one syntactic error in particular, the absence of constituents (subjects, verbs, objects), significantly decreases, pointing to better overall discourse management at fourth grade. On the other hand, some morphological errors like the incorrect use of determiners, the incorrect use of the possessive, incorrect subject-verb agreement, tense misuse, or incorrect derivational morphology continue to pose problems for fourth year students. With respect to determiners, the surprising significant increase in this error subtype at level four could be partly explained by the much more frequent use in fourth year students' essays of these items, as a further revision of the compositions shows. In addition, Thewissen (2013) found out that the incorrect use of determiners was strongly associated with the lower intermediate B1 level and markedly decreased by the time learners reached the B2 upper intermediate level. In our study, fourth year students are at a low intermediate B1 level, which could explain the regression trend displayed by these errors.

In the case of the possessive, subject-verb agreement, and tenses, the non-progressive tendency is disappointing, as a great deal of time and effort is spent on these grammatical items in the students' curriculum. With respect to tenses, Thewissen (2013) also found out that tense usage constituted a rather improvement-resistant area for her EFL groups. While tense errors were found to be improvementresistant in spite of the strong pedagogical attention they receive in secondary education, it is possible that errors in derivational morphology might be improvement-resistant partly because, with the exception of the formation of the comparative and the superlative, it is not a central concern in the classroom.

With respect to lexical progress, there is not a significant increase in lexical competence as proficiency increases, unlike the results obtained by previous studies (Thewissen, 2013; Verspoor et al., 2012). In part, this could reflect the proficiency level of the groups investigated here. As Thewissen (2013) found out, lexis progresses most strongly from the intermediate to the advanced levels. Similarly, Verspoor et al. (2012) argue that students focus on lexical matters at the higher stages of high school. Our students, who are at a low intermediate level, may have not acquired enough command of the main areas of syntax and grammar to leave room for lexis to develop.

In addition to grammar, syntax, and lexis, the present study also traced the developmental trajectories displayed by errors in important L2 areas such as punctuation and spelling. In line with a previous work by Thewissen (2013), our study shows that spelling errors diminish in a significant way 
as proficiency increases. On the other hand, punctuation errors remain an improvement-resistant feature across proficiency levels. This error, which involves missing punctuation markers and the confusion between two punctuation markers, shows no sign of improvement as proficiency increases. This constitutes a key finding, as spelling and punctuation tend to be under-researched areas in second language acquisition and teaching, especially from a developmental perspective.

In general, we find that, in line with results by Thewissen (2013), errors tend to develop in a nonlinear way. Although there are more instances of progress, we also find instances of error stabilisation and regression type of development. Following Thewissen's (2013) argument, we state that stabilisation and regression should not be negatively interpreted in the sense that a significant amount of learning has not taken place. Although errors remain in terms of raw occurrences, they may in fact at times be the result of growing L2 capacities with increasing risk taking, or a sign that increasing complexity is at play.

\section{Conclusion}

The present study has aimed at identifying the development shown by two EFL groups, showing a significant trend of development in written competence from first to fourth grade in both groups, indicating that the measures of fluency, accuracy, and grammatical and lexical complexity progress at the same rate.

Nevertheless, we can clearly perceive changing relationships among the constructs used to measure second language writing--namely, complexity, accuracy, and fluency--, and, in turn, between them and the holistic writing scores in the two analysed levels. This irregular pattern can be explained in LarsenFreeman's (2006, pp. 614-615) terms: "We need a more dynamic view of language and of its learning" as "the messiness is not 'noise', but rather a natural part of dynamically emergent behavior assembled by the individual." In fact, as other practitioners have already stated when referring to SLA development, progress in constructs such as the ones studied here--CAF--is highly variable and not linear, and shows different patterns (Rosmawati, 2014, pp. 91-92).

Besides identifying the development shown by the EFL groups, the present work has also contributed to the field of written competence in other ways. Thus, in addition to grammar, the study has also shown the developmental path errors follow in important L2 areas such as syntax, lexis, spelling, and punctuation, all of which have received scarce developmental attention to date. Thus, this study revealed an improvement both in syntax and spelling as proficiency increases whereas no significant increase in lexical competence is observed. With respect to punctuation, punctuation errors remain an improvement-resistant feature with no sign of improvement as proficiency increases.

Moreover, this study has presented a number of insights for EFL learners, insights that are encouraging on the whole as progress was a regular trend among the learners being studied, who mainly learned English in an instructed rather than in a naturalistic setting.

\section{References}

Godfrey, L., Treacy, C., \& Tarone, E. (2014). Change in French second language writing in study abroad and domestic contexts. Foreign Language Annals, 47(1), 48-65.

Knoch, U., Rouhshad, A., \& Storch, N. (2014). Does the writing of undergraduate ESL students develop after one year of study in an English-medium university? Assessing Writing, 21, 1-17.

Knoch, U., Rouhshad, A., Oon, S. P., \& Storch, N. (2015). What happens to ESL students' writing after three years of study at an English medium university? Journal of Second Language Writing, 28, $39-52$. 
Larsen-Freeman, D. (2006). The emergence of complexity, fluency, and accuracy in the oral and written production of five Chinese learners of English. Applied Linguistics, 27(4), 590-619.

Larsen-Freeman, D. (2012). Complex, dynamic systems: A new transdisciplinary theme for applied linguistics? Language Teaching, 45(2), 202-214.

Lorenzo, F., \& Rodríguez, L. (2014). Onset and expansion of L2 cognitive academic language proficiency in bilingual settings: CALP in CLIL. System, 47, 64-72.

Navés, T., Torras, M. R., \& Celaya, M. L. (2003). Long-term effects of an earlier start: An analysis of EFL written production. In S. H. Foster-Cohen \& S. Pekarek Doehler (Eds.), EUROSLA Yearbook 3 (pp. 103-129). Amsterdam: John Benjamins Publishing Company.

Rosmawati, R. (2014). Dynamic development of complexity and accuracy: a case study in second language academic writing. Australian Review of Applied Linguistics, 37(2), 75-100.

Thewissen, J. (2013). Capturing L2 accuracy developmental patterns: Insights from an error-tagged EFL learner corpus. The Modern Language Journal, 97(S1), 77-101.

Verspoor M, Schmid, M. S., \& Xu, X. (2012). A dynamic usage based perspective on L2 writing. Journal of Second Language Writing, 21(3), 239-263.

Wolfe-Quintero, K., Inagaki, S., \& Kim, H.-Y. (1998). Second Language Development in Writing: Measures of Fluency, Accuracy, and Complexity (Technical Report \#17). Honolulu: University of Hawai ${ }^{i}$, Second Language Teaching and Curriculum Center.

Yang, W., \& Sun, Y. (2015). Dynamic development of complexity, accuracy and fluency in multilingual learners' L1, L2 and L3 writing. Theory and Practice in Language Studies, 5(2), 298-308.

Yang, W., Lu, X., \& Weigle, S. C. (2015). Different topics, different discourse: Relationships among writing topic, measures of syntactic complexity, and judgments of writing quality. Journal of Second Language Writing, 28, 53-67. 